\title{
IV. On the importance of studying and preserving the languages spoken by uncivilized nations, with the view of elucidating the physical history of man
}

Dr. Hodgkin

To cite this article: Dr. Hodgkin (1835) IV. On the importance of studying and preserving the languages spoken by uncivilized nations, with the view of elucidating the physical history of man , Philosophical Magazine Series 3, 7:37, 27-36, DOI: 10.1080/14786443508648651

To link to this article: http://dx.doi.org/10.1080/14786443508648651

曲 Published online: 01 Jun 2009.

Submit your article to this journal $\pi$

Џll Article views: 4

Q View related articles $\llbracket$ 
IV. On the Importance of Studying and Preserving the Languages spoken by Uncivilized Nations, with the view of elucidating the Physical History of Man. By Dr. Hodgkin.*

B EFORE proceeding to the objects which it is my design to lay before you, I would beg leave to take a rapid glance at the range which our Association may be considered to embrace. The study of language may, I conceive, be taken up onseveral distinct grounds : 1st. It may be considered metaphysically, by which I mean the consideration of language generally, as the means of giving expression to the feelings and operations of the mind. To this head might belong the question whether language is coeval with the creation of man, or has been gradually worked out by the development of his faculties, having nothing more than the mere capability of utterance as the original material with which to work. I confess that whilst it is impossible to doubt the progressive development of language, $I$ am inclined to unite with those who admit the former proposition. The metaphysical philologist may nevertheless pursue his speculations and inquire hypothetically into the mode in which language might be progressively built up to satisfy the wants of man. With this inquiry, however, I have little inclination to meddle, but I would take this occasion to mention an interesting essay in some degree bearing on this subject, recently written by Benjamin Harrison, jun., of Christ Church, Oxford. 'To this same division of the subject belong the general or universal principles of grammar. 2ndly. Another division of the subject, to which there is some difficulty in giving a name, forms a most essential part of what are called the Belles Lettres. It has not so much to do with the wide range offered by the numerous languages spoken in different parts of the globe as with the profound and critical knowledge of a few to which common consent has given a prominent position. These are studied in all the varieties of style and idiom as well as in the modifications which at different periods they have exhibited. This branch of the subject necessarily requires an intimate and minute acquaintance with the best authors who have written in these languages; and the individual who has successfully devoted himself to this branch of our subject, is considered par excellence a learned man and a great scholar. It is not my object to detract from the estimation which pure and elegant Latinity and an intimate acquaintance with the dialects, idioms, and metres of the Greeks have by common consent

* Read before the Philological Society by Dr. Hodgkin, in the course of the present session, and now printed with the permission of that Society, in order to make known some of the suggestions contained in it. 
conferred; but it is not in my power to engage your attention in this department. There is another, the 3rd, which I shall mention, which seems more associated with the studies of my own profession; this may be styled the physiological department of philology. To this department belong the interesting researches respecting the production of the vowel sounds, the modification of the voice by the movements of the larynx and the cooperation of the tongue, teeth, lips, and nose. It is not, however, in this department that I propose seeking this evening's occupation, yet I would remark in passing that there are certain modifications of language which it seems necessary to refer to this department, and which cannot fail to introduce a difficult complication, and even serious errors, if they are allowed to be blended with the points of inquiry which legitimately belong to the next division which $I$ shall have to notice. I allude to certain modifications and transitions of sounds which probably pervade all languages, as the result of physiological or organic causes, rather than as proceeding from their mutual relationship as branches of a particular stock. Although it is not my intention to enter minutely into this question, I shall offer a few examples by way of illustration: the substitution of one letter for another is a modification of the kind to which $I$ am alluding. Thus the $B$ is changed into $\mathrm{a} V$ in converting the Latin Diabolus into the Italian Diavolo. A similar change seems to have taken place with the modern Greeks, who say vivlos for biblos $\left(\beta_{1} \beta \lambda_{0}\right.$ ) $)$, and vasilefs for $b a-$ sileus $(\beta \alpha \sigma \downarrow \lambda \varepsilon v \xi)$. It may, however, be questioned whether this is not the true ancient pronunciation preserved by the descendants of the Greeks, from which other nations have seceded, yet I am aware that there are strong reasons for doubting that this is the case. That this change is not a characteristic of a particular stock in language, but rather one of those changes which may be common to them all, and be referrible to some physical cause, may be inferred from the fact that a similar substitution is to be found on the north coast of Africa amongst persons who speak Arabic*. I observed this in a gentleman from Morocco, and I found that his substitution of $\mathrm{B}$ for $\mathrm{V}$, - which I think he made reciprocally, so that he would have said 'Biridi certat vacca benafro,'-was connected with a deficiency in the perception of the sounds of these two letters. He could distinguish no difference between Bacca and Vacca. The substitution of $\mathrm{V}$ for $\mathrm{W}$ and $\mathrm{W}$ for $\mathrm{V}$, which is so characteristic of the vulgar London pronunciation, seems to be

* I have noticed several instances of the similar substitution of one letter for another in the vocabularies of different dialects of the Polynesian language. 
of precisely the same character. An individual who exhibited this peculiarity asserted that his ear could detect no difference between Weal and Veal, Winegar and Vinegar. Whether this insensibility be general amongst those who have acquired this vulgar London peculiarity I am not prepared to say, but I have known a similar insensibility to exist where another substitution of the same kind had taken place. In some parts of Worcestershire and Herefordshire a striking error prevails in the use of the aspirate; we hear it employed where it should be suppressed, and it is suppressed where it should be employed. Although this is done so systematically that it seems like the result of design and principle, yet, as $I$ have just stated, I know that it may take place from a want of perception of the difference existing between the two sounds*. I heard a gentleman from that district say that he could not distinguish as from has. I am unable to say how far changes of this kind are to be attributed to a defective appreciation of the sounds produced, but I believe there can be little doubt that such changes are rather to be attributed to a want of aptitude in the organ producing than in the organ perceiving the sound. A cause of this latier kind operates to prevent many persons from pronouncing the $\mathrm{TH}$, to which, in consequence, they give the power of T or of $D$. A similar difficulty occasions the $\mathrm{L}$ to be pronounced like $\mathrm{R}$, as, for example, "the Rong grories of majestic Rome," for the Long glories, \&c. Children, in learning to speak, often, transiently, exhibit difficulties of this kind, which they for the most part speedily surmount, unless the difficulty be very great, in which case it may become permanent.

The commutation of one letter for another, as is exhibited in the declinable parts of speech, in the composition of compound words, and also in the concurrence of words in a sentence, of which there are so many striking examples in the Greek language, are doubtless to be referred to some physical cause which may sometimes be found in the greater facility of utterance, and at others in the more agreeable sound conveyed to the ear. The manner of contraction from double vowels to diphthongs, and from long vowels to short, is to be referred to a similar cause, as being rather dependent on a physical cause than to be regarded as a peculiarity connected with a particular language. The contraction of $\mathrm{OI}$ into $\mathrm{I}$ in Greek seems to be quite analogous to the vulgar pronuncia-

- An instance illustrative of this is within our own knowledge, in which a person who was originally incapable of distinguishing between aspirated and unaspirated sounds, and who therefore uttered them indiscriminately, has gradually acquired both the perception and the right utterance of them.-EDIT.] 
tion of pint and pison for point and poison. It is by no means improbable that some of these peculiarities of pronunciation and the predominance or suppression of certain sounds in particular districts, although proceeding from physical causes, and therefore to be regarded as distinct from those characters which indicate connexion with a particular stock, may nevertheless be characteristic of a particular race, the organic peculiarity prevailing, like those of colour, form of the head, expression of countenance, stature, and the like, from hereditary transmission. 'That peculiar dialect of English spoken by negroes when living as an enslaved or otherwise oppressed race amongst the English or their descendants, though partly to be ascribed to the neglect of their education and to the encouragement which whites give to this dialect, by themselves falling into it when conversing with negroes, is doubtless principally to be ascribed to the same physical causes which give a characteristic softness to several of the languages on the west coast of Africa, and thus, like the colour of their skin and the form of their features, indicates the stock from whence they are derived, independently of any infusion of words from their own languages with which they may have corrupted the English. The investigation and classification of these changes, influenced by physical causes, might greatly facilitate the labour of those who may apply themselves to the acquisition of several languages, as well as aid those investigations which more particularly fall under the class of which I am next to speak.

The fourth and last division of the subject may perhaps be called the Natural History of Language, its object being to investigate and classify the numerous languages which are spoken upon the face of the globe; to refer them, as far as they admit of being so traced, to different primitive stocks or languages, from which there is reason to apprehend that many of them have proceeded as from a parent or common stock; and to discover, as far as inherent and collateral evidence can render possible, the modifications which the intermixture of language derived from a different stock may have produced, and the time and mode by which these changes by infusion have been brought about. These inquiries are perhaps the most important which can be undertaken for the elucidation of the physical history of man; this division of the subject may therefore be regarded as one of the most interesting and important in which man can be engaged. Although the arduous and successful labours of many distinguished philologists, amongst whom must be especially mentioned Herder, Adelung, Vater, W. and A. Humboldt, Rask, Klaproth, Prichard, Mars- 
den, Grotefend, Crawford, \&c., have done much to excite an interest in this subject, not only in its elucidation, but by extending the inquiry into new regions, yet it is still very far from having obtained the estimation and encouragement which it merits. If I am not greatly mistaken, the thorough investigation of language, on this extensive scale, is absolutely essential to the philologist and to the antiquary or historian, to render theirs integral sciences. Without it their deepest researches and most successfully rewarded exertions only go to the production of a fragment, which, though mighty and splendid, is but a fragment, failing to convey a just idea of the whole. In this view of the subject, Philology and History may be considered somewhat in the same state as the science of Botany would be were it based solely upon the Flora of a particular district; and some of its cultivators may be compared to the ingenious and successful florist who brings out the varieties and beauties which a few species are capable of producing, rather than to the Linnæuses, the Jussieus, the Decandolles, and the Browns. It may perhaps be more correct to compare the state of that branch of Philology which we are now considering to Geology at the time of Buffon, when many and valuable detached facts had been found out and recorded, when the importance of the conclusions to which they might lead were acknowledged, but when these conclusions could not be drawn, and when that great man and some others trusted to supply the deficiency by systems wrought out by their own vigorous imaginations.

If there be any value to be attached to Philology on the comprehensive scale to which I have alluded, we must have a great accession of numerical strength in the class of patient and able observers who may be content to amass facts, both in language and on collateral subjects, without any ruling bias as to the result to which these observations may seem for a time to tend. This is the course which has been successfully pursued with respect to Geology, and which has made it perhaps the most popular subject of investigation of the present day. There is, however, an important difference between the pursuit of Geology and that of Philology to the extent which I am pointing out. If the philological investigations are the more difficult and laborious, and are further removed from the reach of those who may feel an interest in the pursuit, and if it be on this account a less inviting science, there are reasons which do not exist in the case of Geology, or perhaps in any other science, to urge to the prompt and zealous pursuit of it. The geological facts which escape observation or record in this year, or even in this century, may be investigated with equal or greater success in centuries to come. The same may be said 
of almost every other science except that of Philology in its most comprehensive sense. The precious materials with which alone this fabric can be constructed are like the fleeting moments of time itself, which are removing them irrevocably from our research. It becomes therefore a matter of very serious consideration for those who feel the importance of Philology, or rather of that branch of it with which we are now occupied, to bring into its service without delay all the available strength which can be mustered.

I must confess that my object in bringing this paper before my fellow members of the Philological Society has been to submit to their judgement certain measures which I have been led to believe might, with their sanction and support, be made very successfully to conduce to the investigation of this branch of Philology as well as to other researches intimately connected with it.

Before I proceed to offer these suggestions it may not be amiss to take a superficial survey of the present state of the subject, in order that we may have before us, not only the vast extent of the present deficiency, but also some of the grounds of encouragement which prompt to perseverance notwithstanding the apparent discouragement which exists.

I shall adopt as the basis of this sketch the tabular view which is given by my excellent friend Dr. Prichard, which, although it requires alteration in some points, is, I apprehend, the most correct general survey that we at present possess *.

From this table it appears that the Indo-European, the Western Asiatic, the Northern Asiatic and Eastern European, and the Chinese and Indo-Chinese, including those known to have existed as distinct, with those which at present do so, comprise nearly two hundred nations, to which we may ascribe forty-one languages, besides many which are unknown or not mentioned.

According to the same authority we are at present moreor less acquainted with upwards of forty different African races, several of which are numerously subdivided. There are above twenty ascertained languages, and of some of these there appear to be various dialects ; and it is admitted that there are besides thirtyeight languages wholly unknown to us. Amongst the comparatively recent attempts to increase our knowledge of the African languages, I may mention that my friend Jomard, a member of the French Institute and one of the Commission

- [A summary classification of languages purporting to carry still further their natural and ethnographical arrangement, has been given by $\mathrm{Mr}$. Beke, in his Origines Biblica, ch. x. p. 23l-235, and also in his 'Views in Ethnography, \&c.' published in Jameson's New Edinburgh Phil, Journ. for April last._Edix.] 
d'Egypte, has paid considerable attention to the Jaloff language and has composed a grammar, and I believe a dictionary of the same. Hannah Kilham, a minister in my own society, whose zeal led her to make three voyages to Africa, reduced as many as five or six African languages, besides the Jaloff, to a written form. A laborious article has been written on the Birbir language. The missionaries in Southern Africa have paid some attention to the languages spoken in that quarter, and the languages of the Copts and Abyssinians have not been neglected.

The widely scattered inhabitants of the islands of the Indian Archipelago and Pacific Ocean compose twenty-four groups, which seem to be referrible to two or three principal divisions. In many instances the languages spoken by these groups are confessedly allied. They are by most admitted to have more or less affinity to the Malay, properly so called. In some instances the languages are unknown, and in others they are said, but upon what authority I know not, to be quite peculiar. The similarity between the languages spoken in several of these groups was noticed by Captain Cook, and has been confirmed by many voyagers since his time. The subject of these languages has been scientifically taken up by Marsden and Crawford, by some German philologists, and by missionaries employed by this country. Articles on this subject have lately appeared in the Quarterly Review, and I have recently been informed that Baron W. Humboldt is at present engaged in a work on these languages*. I must not attempt to enter into any of the views of these authors, but I cannot omit to notice the work and views of another author which appear to me to deserve considerable attention. I allude to the Essay of Dr. Lang on the origin and migration of the Polynesian nation. One of the objects of the Doctor's work is to show that the several dialects spoken in the islands of the Pacific Ocean are branches of the Malay stock; and again, that the Malay language, with its ramifications, is of Asiatic origin, and if not derived from the Chinese, is at least related to it. He meets the objection which might be raised from the fact that the Polynesian and other branches of the Malay stock are not so monosyllabic as the Chinese language, by observing that the former are often lengthened by prefixed or suffixed particles, which seem to be added in order to increase the

* Since this paper was read to the Philological Society, this excellent man and profound philologist has paid the debt of nature. Of the state in which he has left the paper here referred to we can give no information. Baron W. Humboldt's Posthumous Works, including the memoir in question, have recently been announced and preparing for publication.-EDIT.

Third Series. Vol, 7. No. 37. July 1835. 
number of vowel sounds. Thus, the word tong, which signifies east in the Chinese, is converted into tonga in the language of New Zealand. He further notices the prevalence of particular sounds, as that of the $n g$, which occurs either at the beginning or the end of words in both languages, and of the particles $e$ or $y, p a, p e, t e, k a$, and $k o$, or $t o$, which are of frequent use in them, and, as it would appear, in similar modes and for similar purposes. Besides these points, indicating a similarity in character, there are some in which there is an evident similarity of meaning, which seems to indicate still more strongly than the instances last mentioned the absolute affinity of these languages.

Having endeavoured to show that the Malay language is a kindred tongue to the Chinese, he points out that the language spoken by the Malays properly so called, has received, at two different periods, important additions from distinct languages, in a manner somewhat similar to that in which the AngloSaxon, the original of our own tongue, became blended with Norman-French. These admixtures, or infusions as Dr. Lang calls them, consisted, in the case of the Malay language,

1 st, Of the introduction of a considerable number of Sanscrit words. This modification of the Malay language appears to have been accompanied by a corresponding change in the religion of the Malays, who are supposed to have adopted that of their Sanscrit teachers. 2nd, The next infusion which the Malay language received was from some of the enterprising followers of Mahomet, who introduced both the language and the religion of the Koran. This introduction of Sanscrit and Arabic words into the Malay language appears to explain in a satisfactory manner some of the differences between the Malay language as it exists at the present day and the dialects which are found in those widely scattered islands, from Madagascar to Easter Island, the inhabitants of which are generally admitted to speak a language related to the Malay. The Polynesian language, consisting of several closely allied dialects, appears to have been derived from the Malay before it had received the Arabic or even the Sanscrit infusion, and consequently points to a very remote period, at which the occupation of those islands commenced.

Dr. Lang endeavours to show that this connexion, as indicated by the state of the language, is confirmed by many features of resemblance between the present or past habits of the Oceanic islanders and the Asiatic race from whence they are supposed to have sprung. Some of the most striking instances of similarity consist in the separation of the inhabitants into castes, keeping themselves punctiliously from each other; in 
the adoption of a different language according as the person speaking is of one class and the individual addressed is of another; in their treatment of females; in the superstitious observance of Taboos; in the possession of the rite of circumcision; in some of their games; and in the chewing of the Betel-nut.

The Doctor devotes some pages to account for the origin of a revolting peculiarity which has characterized nearly, if not all, the widely extended ramifications of the Polynesian race, namely, their propensity to eat human flesh. The Doctor accounts for it by supposing that it originated in the urgent calls of extreme hunger experienced by those who made the long and disastrous voyages which have given a kindred population to widely remote islands. In these voyages, often performed without design, under the irresistible influence of wind or current, the stock of provisions must often have been extremely inadequate, and the starving islanders in their canoes may thus have been impelled to partake of the flesh of such of their companions as may have first perished from want, or they may have sacrificed one or more of their number to sustain the rest. The recurrence of such causes, in conjunction with the warlike habits of the people and their human sacrifices, would tend to encourage a practice which the almost total absence of animal food, excepting fisb, would be likely still further to promote.

I need not, at present, further pursue the analysis of Dr. Lang's work as respects the Polynesian nations' dialects and manners; but before I notice that part of his work in which he endeavours to connect the Polynesian with the American nations, I must mention, from the before-mentioned tabular view given by Dr. Prichard, what appears to be the state of America with respect to its nations and languages. The former appear considerably to exceed 300 , and the latter seem to be proportionably numerous, but of these many are unknown. Notwithstanding that a vast number of these languages are stated to be totally distinct, we have the authority of some excellent philologists, and more particularly that of Baron Alexander de Humboldt, that there is a sort of common genius or constitution pervading all these languages as far as they have been examined, and which unites them into one group, whilst it distinguishes them from nearly or quite all others. A more recent traveller, Dr. Von Martius, of whose interesting memoir on the state of the civil and natural rights of the aborigines of the Brazils a translation is given in the Journal of the Geographical Society, confirms the fact of the very great number of the American languages, and mentions that in Brazil alone more than 150 languages and dialects are spoken, 
by more than 250 nations completely broken up and mostly incapable of communicating with each other. The Doctor adduces this statement in conjunction with the present state of the American Indian tribes in support of his hypothesis that the American race is altogether distinct from the rest of mankind, and that the uncivilized tribes with which we are at present acquainted are the debris of one or more nations who, having attained civilization, subsequently relapsed into a state of barbarism, which allowed of their being broken up into distinct nations and tribes, whose migrations during countless ages has brought them into the deplorable state in which they now exist, and which he thus describes:

"In fact, the present and finture condition of this red race of men, who wander about in their native land, without house or covering, whom the most benevolent and brotherly love despairs of ever providing with a home, is a monstrous and tragical drama, such as no fiction of the poet ever yet presented to our contemplation. A whole race of men is wasting away before the eyes of its commiserating contemporaries; no power of princes, philosophy, or Christianity can arrest its proudly gloomy progress towards a certain and utter destruction." (Journal of the Royal Geographical Society, vol. ii.)

Though I shall not stop to combat this opinion, I cannot refrain from expressing my confident hope that a better fate awaits that interesting portion of the human family, and that Europeans and their descendants, in laying aside the atrocious and exterminating policy which they have too long adopted towards those who have preceded them in the occupation of America, will yet be able to redeem their character by successfully pursuing a more liberal and humane system, which it is truly gratifying to observe they are at length, at least in some instances, disposed to substitute for it.

[To be continued.]

V. A Catalogue of Comets. By T.J. Hussey, D.D., Rector of Hayes, Kent.

[Continued from vol. iv. p. 352.]

[The Chronology employed is that of Petau or Petavius.]

A, the comet of 1680. B, that of 1652. C (Halley's), that of $168 \%$. D, that of 1759 . E, that of 1661 . F, that of 1677. $G$, that of 1556 . H, that of 1665 . I, that of 1585 . $\mathrm{K}$, that of 1744. L, that of 1737 . 